believed in, will be certain to give undue prominence to that connexion. It is ouly by taking a number of examples consecutively over a long perion that this disturbing element of choice can be eliminated. Where this is done the results, as I have shown, are not very various, and non-rheunatic chorea is exhibited in overwhelming excess of the rheumatic, the percentage of the former varying from. 75 to 85 .

But it is said the rheumatism with which chorea is associated appears in the families rather than in the patients themselves. It is impossible, of course, to test this position unless some arbitrary limit is assigned to the relationship. If we do but seek far enough, rheumatism is to be found in every family in the kingdom. I have only noted this point in regard to the second series of 49 cases, and have restricted the inquiry to the immediate family of the patients-that is to say, parents and brothers and sisters, including thus a large number of individuals. The result is as tollows: Rheumatism is in the fanily history of 12 patients out of the $49 ; 5$ of these 12 have themselves had rheumatism, and 7 have not. In 1 , or possibly in 2 , of the 5 rheumatis patients, rheumatism was, or might have been, the immediate cause of the chrrea. In 3 of them the cause was known to be fright. There were 8 patients out of the 49 who were not rheumatic themselves, but of rheumatic family. I do not quote these figures as conclusive, or even wholly reliable. So far as they go, and are accepted, they do not confirm the assertion that choreic children have, as a rule, near relatives who are rheumatic. We may well hesitate to believe a doctrine to which the statistics of rheumatism give no support. At any rate, if rheumatic parents transmit their morbid peculiarities to their children, they may be trusted to transmit first of all a liability to rheumatism. We are thus brought back to consider the question as regards the children themselves, since it is certain that if these are choreic in excess, they must still more be rheumatic in excess.

There is reason to believe, from the figures that have been quoted, allowing sufficient room for error :-

1st. That the proportion of chorea showing antecedent rheurnatism does not exceed 25 per cent. of the whole number where children up to twelve years old are taken (viz., 20 per cent. in my own 100, and at the rate of something under 26 per cent. in Dr. Dickinson's 71); and somewhere between 26 and 28 per cent. (viz., 26 per cent. in St. George's 50 , and 26 or 28 per cent. in Dr. Peacuck's 92) where there is no age limitation.

2nd. That the number of instances where rheumatism, in whatever form, is immediately connected with the chorea is very small; being 4 per cent. in my own cases, 7 in Dr. Dickinson's, and from 7 to 8 in Dr. Peacock's and in Dr. Owen's (St. George's).

3rd. That in the great majority of cases of chorea occurring in children supposed to have been rheumatic, the im. mediate exciting cause of the chorea is no other than that which suffices to produce the same aflection in other children who have never been rheumatic.

It is obvious that by no method of argument can these conclusions be made to tell in favour of that intimate connexion between chorea and rheumatism which some contend for. Let us say, for example, that 100 instances of chorea yield 25 with a history of antecedent rheumatism. Of these there will be a certain small number representing the proper proportion of rheumatic subjects, which we might expect to find in 100 individuals. What this number should be we know not. Suppose that, on an average, only 5 per cent. of our countrymen get rheumatism in childhood. We have then 20 out of 100 choreic patients charged with rheumatism in excess of the proper number. But physical pain is a well-recognised cause of chorea, so that of the cases that arise immediately out of rheumatism (from 5 to 8 per cent., as we have seen), some may be accounted for, not because of the rheumatism as such, but because of the pain that attends rheumatism. This would still further reduce the number.

There would still remain the examples of chorea to which I have alluded in the first paper as occurring in immediate connexion with acute rheumatism, and in virtue of which it may be necessary to admit that the one disease actually gives rise to the other. Although too few to affect perceptibly statistical tables, there are now a considerable number of such cases in our literature. In most of these the subjects are not children, but young people in whom violent and often fatal clonie convulsion (whether chorea or not) arises immediately out of acute articular rheumatism, or interrupts or may even precede it. Such symptoms cannot be dissociated from the other phenomena of the disease which they accompany. They furnish examples, along with those of acute delirium and the several forms of cerebral embolism, of the nervous accidents to which the condition of the blood during acute rheumatic fever gives occasion. In their origin, therefore, no less than in their character and choice of subjects, these convulsions are quite distinct from the chronic disorder of childhood which we are now discussing.

The excess of rheumatism, then, in chorea would seem to be represented, at the utmost, by something between 15 and 20 per cent. - an excess too small to he adduced in support of any intimate connexion between the two, but nevertheless needing to be accounted for somehow. The question, in fact, comes to this: whether to believe that "rheumatism" (of nature undefined) confers this extra liability to suffer from chorea, not immediately, but at some future and it may be distant period; or else to believe that the excess of rheumatism is only apparent, and due to the fact that rheumatism shares with chorea both heart disturbance and limb pains, so that symptoms due to the one affection are easily attributed to the other. If the first supposition be adopted, it will be necessary to insist (for here the evidence of statistics is decisive)-first, that the rhenmatism which predisposes to chorea is seldom connected with it in point of time, a clear interval occurring between the disappearance of the cause and the arrival of the effect; and, secondly, that the rheumatic children who become choreic require the ver same immediate incentive to the disorder as do other child. ren-namely, alarm or mental excitement or nervous shock. If the second supposition be adopted, the prevalent belief in the connexion of rheumatism and chorea is explaiued upon considerations which yet fail to justify it; while in the lessening proportion of rheumatism in our later statistics we see the operation of that still recent knowledge which makes it possible to discriminate the heart affection of chorea from that of bygone rheumatism.

It is not to the present purpose to notice other arguments of statistics against this asserted connexion. These are to be found, as I believe, in the time of life, the sex, and the geographical distribution of chorea and rheumatism respectively, as well as in the fact that while students of chorea are earnestly contending for an alliance of this kind, the students of rheumatism, with their far richer material and ready admission of complications and sequelæ, give no encouragement to such proposals. The doctrine of the rheumatic origin of chorea, however, is too firmly rooted in this country to be much disturbed by such considerations. We no longer seek to verify this connexion, but are rather occupied in constructing some plausible explanation of it. Everyone has prominently in memory numerous instances of rheumatic children who have become choreic; very few consider that in every consecutive ennmeration such cases are far exceeded by the others. Meanwhile the two most prominent and unquestionable facts of chorea pass unregarded: the fact that alarm or mental disquiet is its commonest, and, it may be, its constant cause, and the fact that female children are in overwhelming proportion its favourite subjects.

Wimpole-street, W.

$\longrightarrow$

\section{CASE OF \\ ILIO-FEMORAL ANEURISM SUCCESSFULLY TREATED BY RAPID COMPLETE PRESSURE.}

By Surgeon-Major F. P. STAPLES, ARMY MEDICAL DEPARTMENT.

Private J. H-, 73rd Regiment, a tall, well-developed and apparently healthy soldier, aged thirty-nine years, of nearly fifteen years' service, was admitted into the Royal Victoria Hospital, Netley, on May 7 th, 1879, suffering from ilio-femoral aneurism, haviug been invalided on account of it from India. His medical history was un. important up to the year 1877, when, at Subathoo, a station in the North-west Himalaras, he suffered from an attack of enteric fever. Soon after his discharige from hospital for that illness, in the month of September, he felt a throbbing 
swelling in his right groin, but under the belief that it was of venereal origin, he kept his knowledge of it to himself. He marched soon afterwards with his regiment to Lucknow, a proof of his statement that it was not then very inconvenient. At Lucknow, in March, 1878, he found that he was unable to undergo the severe drills which take place at that season of the year, owing to the swelling having become much more painful. He also suffered at this period from palpitation of the heart. He now sought admission into hospital, where the aneurism was at once diagnosed. The medical officer under whose charge the case fell considered that no operative interference was then advisable owing to the indifferent state of the patient's health, and sent him to England.

On admission at Netley the aneurism, which was on the right side, was globular in shape, and measured about three inches and a half in diameter. It presented all the specific signs of aneurismal tumours. Describing it more accurately in its relation to Poupart's ligament, it was found that, although to the eye the line of this ligament appeared to bisect it, yet nevertheless the major portion of the aneurism was pelvic, or, in other words, its origin was iliac. SurgeonGeneral Longmore, C.B., who in the management of the case gave me the benefit of his large experience, called particular attention to this point with reference to operative interference, and expressed his opinion that there would probably not be found sufficient room to place a ligature upon the external iliac artery, so that, should deligation be determined upon, the operator must be prepared to ligature the common iliac artery.

After full consideration of the case, it was resolved to try the effects of treatment by pressure in the first instance-a plan which concurred with the views of the patient, who expressed very decidedly his determination not to submit to any cutting operation, but had no objection to any other treatment that might be adopted. Arrangements were accordingly made for attempting a cure by complete com pression, or, in other words, by locking the blood in the aneurism by means of an Esmarch elastic bandage and a tourniquet. After a few unsuccessful attempts to maintain the tourniquet in proper position, this was successfully carried out on the 5th of June; and, before proceeding further, I am anxious to express my obligations to $\mathrm{Mr}$. Gaisford, now a surgeon in the Indian Medical Service, for his assistance in keeping the tourniquet adjusted under great difficulties, caused by the restlessness of the patient. The Esmarch bandage was first applied from the toes to a line a little above the origin of the profunda artery. A graduated pad of lint was afterwards applied over the course of the common iliac artery, and a Lister's tourniquet adjusted over the pad. A moderate amount of pressure was then found sufficient to command the circulation through the aneurismal swelling. The pulsation in the aneurism was completely arrested at 9.45 A.M. At 10.15 the Esmarch bandage was removed on account of the excessive pain complained of by the patient, and at 10.45 I directed the removal of the tourniquet for the same reason. I was under the impression at this time, from the report which I received of the pulsation, though perceptibly weaker, not having entirely ceased, that the experiment had in a great measure failed, and I resolved to repeat the treatment under chloroform. On examining the patient with this view the next morning, I was pleased to find that any further steps were unnecessary, the aneurism being quite consolidated and pulaeless. The limb was then immediately treated in the usual way for ensuring rest and warmth. The subsequent history of the case needs but little remark, as it was one of uninterrupted recovery. For a few days the affected limb had a lower temperature than the other, with a somewhat paler aspect, and the patient complained of a sensation of "pins and needles" in it. These symptoms, however, were never such as to cause the smallest anxiety, and, clinically, perhaps one of the most interesting features of the case was the apparent facility with which the collateral circulation became established. As regards the aneurism itself, it gradually decreased in size, so that at the end of a month from the application of the pressure it merely felt like a simple adenoid tumour, and in size was not larger than a walnut. On the 4th of August, or after two months, it was scarcely distinguishable from one of the inguinal glands.

Remarks. --The foregoing case furnishes a record of the success of pressure in the treatment of an ilio-femoral aneurism of nearly two years' duration. It is also a good example of the success attending that form of rapid pressure which has received the name of absolute or complete tem. porary compression. Lastly, it may be taken as evidence that, in the application of rapid pressure to pelvic aneurisms, the value of that means is much enhanced by the use of Esmarch's bandage as the lower tourniquet.

Rapid compression being now so fully recognised as the most appropriate form of this treatment for pelvic and abdominal aneurisms, chiefly on account of the instrumental difficulties of carrying out the graduated method, it is not necessary further to allude to it in connexion with this particular instance. It may be useful, however, to ask in what class of cases is this treatment most likely to effect its dcsired result? Is it most applicable, for instance, to recent aneurisms, or, in other words, to those which can be emptied of their contents? Or is its practice most likely to be successful in older aneurisms, in the sacs of which fibrinous laminæ have already been deposited? Bearing in mind its effects-viz., the production of blood-clot-it might appear proper to give a negative reply to the first question and an affirmative one to the latter, for the following reasons. In recent aneurisms, and in those in which laminated fibrin has not been deposited, the clot, on account of its large size, would offer great facility to the blood-current to break it up; and as its first contraction need not necessarily carry the sac with it, or rather include the sac in the curative process, it would follow that a facility would be given to the blood. current to act prejudicially by insinuating itself between the two. With older aneurisms, on the other hand, in which fibrinous clot has been deposited, the conditions are different and are such as would appear to favour the success of rapid pressure. In these cases the blood-channel is frequently not greater, and sometimes even less, than the calibre of the diseased vessel, and the clot necessary to arrest pulsation, being thus comparatively small, would, so to speak, offer fewer points of vantage to the disturbing current of the circulation; while the surrounding fibrin, already intimately connected with the sac, would, by its contraction, further reduce the danger from this agency. The above is no doubt speculative reasoning to a great extent, and, as such, the writer begs to apologise for it; but he is not without hope that it may be worthy of the attention of those who are engaged in systematising the treatment of aneurism.

\section{AN ACCOUNT OF A RECENT OUTBREAK OF TYPHUS FEVER IN ST. GILES'S DISTRICT.'}

BY S. R. LOVETT, L.R.C.P.ED.,

MEDICAL OPFICER OF HEALTH FOR ST. GILES'S DISTRICT.

MUCH interest having been evinced in several recent cases of typhus fever which have occurred in the St. Giles's district, and particularly in some of them which originated in an area embraced by a scheme for its improvement under the Artisans and Labourers' Dwellings Improvement Act, $\mathbf{1 8 7 5}$, it may be useful for the facts of the cases, as far as I, as medical officer of health of the district referred to, have been able to ascertain them, to be made public.

For convenience of illustration I divide the cases into tro groups.

The first case of the first group occurred on August 22nil, when the house-physician of King's College Hospital informed the medical officer of health of the Strand district that a young woman, Hannah L__-, aged thirty, was admitted to the hospital the previous day from Bear-yard, Lincoln's-innfields, in the Strand district, suffering from typhus fever. On receiving this information the medical officer visited the house, and ordered the rooms to be disinfected, and ascertained that the woman had slept there about five nights be. fore she went to the hospital for advice, and that previous to her residence in Bear-yard she lived in Lincoln-court, Drurylane, which is in St. Giles's district. The medical officer of the Strand district gave me the history of the case as far as he knew it, but it was of little use to me, inasmuch as the houses in Lincoln-court, being included in the area con-

I A paper read before the Society of Medical Officers of Health. 